Sociology: Computational Organization Theory

\title{
Sociology: Computational Organization Theory
}

\author{
Kathleen Carley \\ Dept. of Social and Decision Sciences \\ Carnegie Mellon University
}

June 1994

\section{Keywords}

Simulation; organization theory; organizational learning; social networks; expert systems

Citation: Kathleen Carley, 1994, "Sociology: Computational Organization Theory." Social Science Computer Review, 12(4): 611-624. 


\section{Sociology: Computational Organization Theory}

Throughout the history of organization theory there has been an implicit goal of developing an understanding of organizations in terms of the situated action of the agents within them and the position of the organization itself in the larger environment. Weber $(1922,1968)$ sought to understand organizations in terms of the causal relations that shaped the multidimensional phenomenon we refer to as the organization. His approach was a combination of the inspection of "ideal types" and historical analysis. His work and that of Taylor (1911), Fayol (1949) and others in the scientific management area shaped early work on organizations. Collectively, this early work suggested that a science of organizations could be built around models of the agents in the organization performing organizational tasks. These models could be idealizations of reality, but detailed enough to lend insight into and to be tested against historical data. The task was critical, not just due to goal setting, but also because it affected issues such as requisite skills, timing, level of training, number of personnel, and so forth.

Cyert and March's A Behavioral Theory of the Firm (1963) arose out of this early work on organizations as collections of intelligent agents. Indeed, Cyert and March (1963) stands as a landmark for organizational theorists interested in formal models. Their work demonstrated the organizational impacts of bounded rationality and the value of process models for organization theory. Cyert and March characterize their research strategy using four points; (1) focus on a small number of economic decisions, (2) develop process oriented models, (3) link models to empirical data, and (4) develop a theory with generality beyond a specific firm.

Another line of research, with roots that can also be traced to Weber's interest in external context, is that on organizations as nodes in networks. The work of DiMaggio (1986) and DiMaggio and Powell (1983) on organizational fields and that by Burt (1992) on structural holes points to the importance of the inter- and intra- organizational networks in directing the organization's actions and the actions of individual within these organizations. Collectively, these works and many others show the power of the network paradigm for describing organizations and markets. Computational tools for analyzing such networks are making it possible to blend this work with that on organizations as collections of intelligent agents into a unified formal framework.

Today, these lines of research on organizations are merging in the area of computational organization theory. Computational organization theory is an inter-disciplinary scientific area whose research members focus on developing and testing organizational theory using computational technology. The community shares a theoretical view of organizations as collections of processes and intelligent adaptive agents that are task oriented, socially situated, and technologically bound. Behavior within the organization is seen to affect and be affected by the organization's position in the external environment. The community also shares a methodological orientation toward the use of computational techniques (e.g., simulation, emulation, expert systems, computer-assisted numerical analysis) for developing and testing theory. Through computational models of organizations we can now begin to formally address the goals put forth by the pioneers of organizational theory.

Organizational theory was influenced early on by the computational approach. Early computational organization theory was influenced by the cybernetics, general systems, the systems analysis movements (e.g., Ashby, 1956; Beer, 1964; Haberstroh, 1965; Chorafas, 1965); research on organizational formalism (e.g., Hage, 1965); interest in bounded rationality (Cyert and March, 1963); 
and process models of social behavior (Dutton and Starbuck,1971; Abelson, 1968). Work by Forrester $(1961 ; 1968)$ in system dynamics spawned an entire line of research (see for example, Judson, 1993; Hanneman, 1988; Hanneman, Collins, Mordit, 1992); as did Cohen, March and Olsen's (1972) "Garbage Can Model," (see for example, the work reported in March and Weissinger-Baylon, 1986).

\section{Modeling Issues}

Today, there is no unified model or framework for characterizing organizations and on which work in computational organization theory rests. Rather, computational organization theory is currently dominated by research employing one of four distinct technological approaches: general organizational modeling, tool development, distributed artificial intelligence, and organizational engineering.

\section{General Organizational Modeling.}

This approach is characterized by the development of models that are used to locate general principles, and to explore general processes, rather than to make specific predictions for specific firms. The models incorporate the use of ideal types, and often abstract away from many of the complexities inherent in real organizations. These models often employ techniques such as numerical enumeration, matrix manipulation, logic, or Monte-Carlo analysis. This area has its intellectual roots in sociology and traditional organization theory. Models are often developed to compare and contrast features of "ideal type" organizations, networks of organizations, or agents. Illustrative models in this area include those by Cohen March and Olson (1972), Patrick (1974), Carley (1992), Glance and Huberman (1994a), and Harrison and Carrol (1991).

\section{Tool development.}

This approach is characterized by the development of computational and formal analysis tools. These tools include the development of m-agent logics, automated theorem provers, computational tools for locating properties of graphs (Krackhardt, 1994), and simulation frameworks for evaluating organizational measures (Lin, 1994). The intellectual roots here vary widely and include graph theory, logic, and statistics.

\section{Distributed Artificial Intelligence.}

This approach is characterized by the development of symbolic models that perform specific stylized tasks such as navigation or surveillance. A critical aspect of many of these models is the way in which the agent's knowledge, and the "shared" knowledge is represented. Other critical components include the way in which this knowledge is searched and/or activated. Some research in distributed artificial intelligence employs general models of cognition that make very strong claims about the nature of agent intelligence (e.g., the work using Soar Carley et al, 1992). This area has its intellectual roots in cognitive science and computer science. Models are often developed to address issues of communication, coordination, planning, or problem solving. Within some of these models agents are treated very generically an there is an implicit assumption that the results are generalizable to networks of computers, networks of software programs, and networks of people. See Bond and Gasser (1988) and Gasser and Huhns (1989) for comprehensive reviews and illustrative papers. 
Sociology: Computational Organization Theory

\section{Organizational Engineering.}

This approach is characterized by the development of highly detailed models often oriented to specific organizations and/or specific industries. The models are often immense and employ details at many levels. Using these models it is possible to develop both policy implications and sometimes to do what-if planning to help the specific organization with various design issues. Illustrative models include HI-TOP (Majchrzak and Gasser, 1991; 1992a; 1992b; Gasser and Majchrzak, 1992), ACTION (Gasser, et al. 1993; Gasser and Majchrzak, 1994; Majchrzak and Finley, 1995), VDT (Levitt et al, 1994; Jin and Levitt, 1994), and TIDES (Reuter et al, 1994).

\section{Modelling Challenges}

Rarely today are organizational models as simple as the garbage can model (Cohen, March and Olsen, 1972) which can be run in a few minutes on a small machine. Rather many, of the models require hours or even days to run a single test and many must be run on high performance workstations. Note, on models with multiple parameters many tests often need to be run with random parameter variations. This can result in weeks to months of data collection.

There are a number of modeling issues that all researchers in this area face. Let us consider six of these - scalability, detail, data input, focus, micro-macro linkage, and data interpretation. Despite the increased sophistication of today's models, in many cases, in order to make the models tractable it is still often necessary to create organizations composed of a small number of agents; e.g., 2 to 13 agents. There is thus an issue of scalability. Do the results from these small organizations generalize to organizations with 100s of employees? Second, in building computational models the researchers need to be careful about whether they are doing emulation or simulation. Emulation is much more exact and allows for predictions on a specific system but often requires much larger or "kitchen sink" models; whereas, simulation is less exact, employs a higher level of abstraction, but may admit the discovery of general principles with relatively sparse models. In part, the tension here is between veridicality and generalizability. In part, the tension centers on the ability to make causal inference. In larger models (those toward the emulation end) the vast number of parameters may make it impossible to engage in complete response surface modeling and so understand the specific cause of any particular result. However, in simpler models (those toward the simulation end) The third issue, data input, refers to the fact that as we build larger models that rely on user input, data input becomes an increasingly onerous task. In particular, in emulation models where we wish to characterize an existing firm, the development of simplified procedures for entering a description of that firm may be as difficult a task as building the emulation model itself.

The fourth issue is near and dear to sociologists and organizational theorists, linking the micro to the macro. Within computational models, this issue takes a very specific form. Often researchers want to model organizations as collections of intelligent adaptive agents but to measure more macro output. Consequently, the computational theoretician must develop an answer to how the linkage is made; e.g., are there processes of aggregations, what behavior emerges and what is built in, and so forth. Often in developing a model new issues of how the micro links to the macro emerge. The final issue is data interpretation. Today with relatively large disk space, computational theoreticians can have there models save vast quantities of results. This has created the need for post-processors, smart agents, and internal graphical and 
statistical packages that can automatically parse the output and locate important results that might otherwise be overlooked.

Theoretical Issues

Within computational organization theory a wide range of theoretical issues have been addressed. Given that computational techniques make it possible to study dynamics (processes and results of change) and non-optimal conditions it is not surprising that many of the topics studied have these features. Among the issues examined are: organizational decision making, organizational culture, organizational learning, organizational design (communication and coordination), organizational dynamics, impact of new technology, and crisis management.

\section{Organizational Decision Making}

The study of organizational decision making has heretofore focused on case studies and formal mathematical models of teams. The latter work has typically focused on how to achieve optimal decisions (DeGroot, 1970), how to optimally allocate resources (Arrow and Radner,1979) or how to reach consensus (DeGroot, 1974; Marschak, 1955). The case studies, however, demonstrate that within organizations, consensus is not necessary, often unachievable, and is rarely the modus operandi for making decisions (March and Weissinger-Baylon, 1986). Further, these studies demonstrate that organizations rarely have the time, access to information, or a static enough environment that it is possible to locate the optimal decision (March and Romelaer, 1976; March and Simon, 1958). Organizational decision making is thus portrayed as occurring in a messier and distributed environment. Computational organizational theorists build on these findings and examine the factors affecting organizational decision making in this messier environment where personnel come and go, there is a single decision maker or a team that need not reach consensus, and the decisions are often made through satisficing rather than because they are optimal (Arthur, 1991; Carley 1990, 1991, 1992; Cohen, March and Olsen , 1972; Beroggi and Wallace, 1994; Davis and Smith, 1983; Masuch and LaPotin, 1976).

\section{Organizational Culture}

Organizational culture and, indeed, culture in general is increasingly receiving attention in the literature. Part of this work stems from a view that culture is key to understanding the formation and maintenance of groups, and, within organizations, their productivity. A key computational piece in this area is that by Harrison and Carrol (1991) who examine cultural differences and their long term implications. Within computational organization theory more generally, culture is raising its head as researchers find that cognitive, structural, and task based constraints are not sufficient to explain organizational behavior. Rather, even with these factors specified there are still often multiple courses of action and multiple roles open to the agents in the organization. Culture, often in the form of setting individual agent "preferences" or "energy" comes into play as a critical determinant of action and role taking(Carley et al, 1992; Carley and Prietula, 1992, forthcoming; Cohen, March and Olsen , 1972; Lin and Carley, forthcoming; Masuch and LaPotin, 1989). Such factors also play a role in what and how the organization learns (Lant and Mezias, 1992).

\section{Organizational Learning}


An area that is receiving increasing attention by computational organizational theorists is learning, and the related phenomena of training, innovation, and diffusion. Among the issues examined are convergence (Lant and Mezias, 1992), entrepreneurship (Lant and Mezias, 1990), type of training (Alluisi, 1991); group action (Macy, 1990), cooperation (1993, 1994a), diffusion and professionalism (Kaufer and Carley, 1993) and structure (Carley, 1992). This work varies in the type of learning model employed from classical learning theory models (Macy, 1990,1991) to detailed artificial intelligence models (Tsuchiya, 1993; Masuch, 1990). For a more detailed review of this area see Lant (1994). This work suggests that individual learning and the organizational training procedures may be the basic building blocks for understanding how individual actions produce and reproduce group outcomes. It also demonstrates the criticality of feedback to organizational performance.

\section{Organizational Design (Communication and Coordination)}

By far, the issue that has received the most attention by computational organization theorists is organizational design. This work has a wide range and covers many different design issues. Some of this work takes the general findings in contingency theory (Lawrence and Lorsch, 1967) and integrates them into a single expert system (Burton and Obel, 1984; Baligh, Burton and Obel, 1987; 1990; 1994). Other studies move beyond classical models of optimal allocation of resources and goods (Arrow and Radner, 1979; Gloves and Ledyard, 1977) and claims about structure (Galbraith, 1977; March and Simon, 1958; Staw, Sanderlands and Dutton, 1981; Weber, 1922) to comparisons of allocation, communication, and command structures (Cohen, March and Olsen, 1972; Carley, 1990, 1991; Carley and Lin, forthcoming; Masuch and LaPotin, 1989).

In all cases, the use of computational techniques have illustrated which of the arguments in the literature are internally consistent with each other. This body of research confirms that there is no one best organizational design; rather, organizational design is highly contingent. This work moves beyond this generic statement to a series of findings that specify how the various aspects of organizational design affect performance under specific conditions. Consequently, this research has refocused the interest of organizational theorists on the tradeoffs inherent in organizational design (Baligh, Burton and Obel, 1987) and neo-Weberian models (Hanneman, Collins, Mordit, 1992). Commonly within the study of organizational design, organizations are modeled as networks of relations among subtasks, among people, between tasks and people (e.g., Cohen, March and Olsen, 1972; Carley, 1992; Krackhardt, 1994; Lin, 1994; Levitt et al., 1994). Also, it is common that these models take a systems (Haberstroh, 1965) or an ecological perspective (Kaufer and Carley, 1993).

Much of the computational work on organizational design focuses on issues of coordination and communication. This work has examined the impact of cooperation on performance, and strategies for cooperating (Cammerata, McArthur and Steeb, 1983; Glance and Huberman, 1993), processes for achieving coordination when agents are distributed across multiple sights (Decker and Lesser, 1993; Durfee, 1988), planning (Corkill, 1979;Decker and Lesser, 1992), and general problem solving (Gasser and Toru, 1991; Davis and Smith, 1983). Models of coordination (Malone, 1987) and tests of their impact on performance (Lin, 1994) have also appeared. Issues of current importance include the impact of organizational design and redesign 
on shared cognition, the development of individual mental models, and job distribution and redistribution in changing technological climates.

\section{Organizational Dynamics}

An area of current interest is that of organizational dynamics. Organizational dynamics refers to the study of the processes and impacts of shifts in organizational designs and the evolution and alteration of organizations. Shifts in organizational design may occur through a variety of processes including evolutionary processes (Crowston, 1994), conscious reengineering (Baligh, Burton and Obel, 1987; Gasser 1993), reactionary processes in response to the environment such as when crises occur (Carley 1991), internal dynamics (Hanneman, Collins, and Mordit, 1992; Hanneman 1988), and learning processes (Lant and Mezias, 1990). Computational models are particularly suited for the study of organizational dynamics as they let the researcher focus on the dynamics by which organizations are designed and redesigned (Cohen, 1986) and the impact of process on specific tasks (see for example Crecine's 1969 work on budgeting). This work brings to the fore a concern with how can organizational performance be assessed when organizations are continually being designed and redesigned or are evolving or naturally changing.

\section{Impact of New Technology}

Some of the current computational models admit the possibility of studying the impact of new technologies, particularly information technologies. This line of research follows from a long standing concern on the part of organizational theorists with technology and communication (Thompson, 1962; Galbraith, 1977) and transform it into models of information systems and technology within organizations (Bonini, 1963; Mezias and Glynn, forthcoming). Such models can be used to do a "what if" analysis and so explore what happens if the technology breaks (Carley, 1991) or is altered (Levitt, Cohen, Kunz, Nass, Christiansen and Jin, 1994) or a new technology is introduced (Majchrzak and Finley, 1995). Using such "what if" studies, preintervention analyses can be done that have the potential to affect policy.

\section{Crisis Management}

Finally, computational organization theorists have approached the area of organizations and crisis. Classic studies on crisis have taken a case study (Shrivastave, 1987; Rogers et al., 1986) or comparative approach (Perrow, 1984; Staw, Sanderlands and Dutton, 1981). The crisis area is one that is particularly amenable to the computational approach. In this area it is difficult to collect data and experiments are often either unethical or suspect. Thus, computational models can be used to go beyond the data and do forecasting and what if analyses that admit multiple factors to be considered (Carley, 1991; Lin, 1994).

\section{Conclusion}

The field of computational organization theory is growing rapidly. In the past six years a cursory analysis reveals at least 40 related publications per year as opposed to the half dozen or so per year prior to this. These publications, however, are spread out over at least 25 journals, 
proceedings from three different conferences, and books. In the past three years, over six workshops in this area have been held in conjunction with the AAAI meetings and the ORSA/TIMS. The growing general interest in sociology with computational approaches (Bainbridge, 1987; 1990; Bainbridge, et al. 1994; Brent, forthcoming; Wolfe, 1991) is reflected in this growing interest in computational organization theory. Finally, within the organization area there appears to be not only growing interest, but an increase in the extent to which later work builds on earlier work and an increase in the sophistication of the models.

Across the field of computational organization theory there are common emphases. First, many computational theoreticians employ network representations for capturing the organization's design. Thus networks are used for linking subtasks to subtasks, subtasks to people, people to people, people to organizations, and organizations to organizations. The use of social network techniques for characterizing and analyzing these configurations is on the horizon. Second, there is an emphasis on process. Organizations are not viewed as static. Processes are seen as more important in establishing agent, task, and organizational boundaries than general traits. And finally, there is an emphasis on change. Computational techniques make it feasible to examine organizations in flux, and to minutely scrutinize the processes by which individuals and organizations learn, adapt, react, and evolve.

Computational organization theory has the potential to change traditional views of organizations. The emphasis on process, task, and change may lead to a more dynamic yet situated view of organizations. The use of sophisticated models of cognition for modeling agents in organizations may give rise to a neo-information processing paradigm. This should in turn improve our understanding of agency and action. The attention to organizations as collections of intelligent agents may lead to a better understanding of the processes whereby groups are formed and reformed. Finally, as the models become increasingly sophisticated issues of informal networks, role, culture, demography, and power begin to appear in these models. As a result, these more comprehensive models may enable us to gain a better understanding of the full ramifications of social and technological changes within the workplace.

There are many types of organizational problems suited to the computational approach. One would use this approach to address issues of suboptimality, to analyze complex multidimensional problems, to examine the impact of critical or lethal events (e.g. crisis analysis), to address the impact of change in the short run, and to address issues of change. Not all issues warrant a computational approach. Finally, the computational approach can provide a practical benefit. With these models, it is often possible to engage in "what if" analyses. To the extent that the models are verified and generalizable to the situation at hand they can provide a mechanism for exploring the ramifications of various policies.

The use of computational techniques is not an "all or none" proposition. Computational techniques can be fruitfully employed in conjunction with non-computational models, human experiments, and empirical data to provide a more rich understanding of organizational behavior. For example, Glance and Huberman (1994b) use simulation to confirm analytic predictions and illustrate atypical behavior. Beroggi and Wallace (1994) combine computational and noncomputational analytic techniques. Heise $(1978,1979,1987)$ employs a combination of computational models and empirical data to predict individual action. Burton and Obel have been at the vanguard in linking simulation and experimentation (1984). Baligh, Burton and Obel 
(1994) could not have developed the Organizational Consultant without extensive analysis of real organizations and testing of their expert system using specific case studies. In the future, one should expect to see an increasing use of simulation experiments to fine tune and help define critical human experiments and field studies. One should also expect to see an increase in the use of simulation aided data analysis. What all this suggests is that use of computational and formal techniques are becoming more accepted, and indeed sometimes indispensable, for organizational research and theory building. 


\section{References}

Abelson, Robert P. (1968), "Simulation of Social Behavior, " In Handbook of Social Psychology, 2nd ed., Vol. 2, edited by Gardner Lindzey and Elliot Aronson. Reading Mass. : AddisonWesley Publishing Co.

Alluisi, Earl A. (1991), "The Development of Technology for Collective training: SIMNET, a Case History," Human Factors, 1991, 33(3), 343-362. (network, training, learning)

Arrow K.J. and Radner R. (1979). Allocation of Resources in Large Teams. Econometrica, 47, 361-85.

Arthur, W. B. (1991). Designing economic agents that act like human agents: A behavioral approach to bounded rationality. American Economic Review Papers and Proceedings, 81, 353-359.

Ashby, W. R. (1956). The effect of experience on a determinant system, Behavioral Science, 1, $35-42$.

Bainbridge, W.S., E.E. Brent, K. Carley, D.R. Heise, M.W. Macy, B. Markovsky, and J. Skvoretz (1994). Artificial Social Intelligence, Annual Review of Sociology, 20.

Bainbridge, William Sims (1987), Sociology Laboratory : Computer Simulations for Learning Sociology, Belmont, CA: Wadsworth Publishing Company.

Bainbridge, William Sims (1990), "Neural Nets and Social Theory : Applications of Artificial Intelligence Technology," Paper Given at the 1990 ASA Meetings.

Baligh, H. R. M. Burton, and B. Obel (1987), "Design of Organizational Structures: An Expert System Method," In J.-L. Roos (Ed.), Economics and Artificial Intelligence, Oxford, UK: Pergamon.

Baligh H.H., Burton R.M. and B. Obel. (1990). Devising Expert Systems in Organization Theory: The Organizational Consultant. In M. Masuch (Eds.), Organization, Management, and Expert Systems. Berlin: Walter De Gruyter.

Baligh H.H., Burton R.M. and B. Obel. (1994). Validating the Organizational Consultant on the Fly. In Carley K. and M. Prietula (Eds.), Computational Organization Theory. Hillsdale, NJ: Lawrence Erlbaum Associates. 
Beer, S. (1964). Cybernetics and Management. New York, NY: Wiley.

Beroggi, Giampiero E. G. and William A. Wallace (1994), "A Decision Logic for Operational Risk Management," In Kathleen Carley and Michael Prietula (Eds.) Computational Organization Theory, Lawrence Erlbaum Associates, Hillsdale, NJ.CHAP 14

Bond A. and Gasser L. (1988). Readings in Distributed Artificial Intelligence. San Mateo, CA: Kaufmann.

Bonini, Charles P. (1963). Simulation of Information and Decision Systems in the Firm, Englewood Cliffs : Prentice-Hall.

Brent E. (forthcoming). Computational Sociology: Reinventing Sociology for the Next Millennium, Social Science Computer Review.

Burt R.S. (1992). Structural Holes: The Social Structure of Competition. Cambridge, MA: Harvard University Press.

Burton R.M. and Obel B. (1984). Designing Efficient Organizations: Modeling and Experimentation. Amsterdam: Elsevier Science.

Cammarata S., McArthur D. and R. Steeb. (1983). Strategies of cooperation in distributed problem solving. Proceedings of the Eighth International Conference on Artificial Intelligence.

Carley K. (1990). Coordinating for Success: Trading Information Redundancy for Task Simplicity. Proceedings of the 23rd Annual Hawaii International Conference on System Sciences.

Carley K. (1991). Designing Organizational Structures to Cope with Communication Breakdowns: A Simulation Model. Industrial Crisis Quarterly, 5, 19-57.

Carley K. (1992). Organizational Learning and Personnel Turnover. Organization Science, $3(1), 20-46$.

Carley K. (1993). Plural-Soar: Towards the Development of a Cognitively Motivated Theory of Organization. Proceedings of the 1993 Coordination Theory and Collaboration Technology Workshops: Symposium Conducted for the National Science Foundation. 
Carley K. and Z. Lin. (forthcoming, 1995). Organizational Designs Suited to High Performance Under Stress. IEEE - Systems, Man and Cybernetics, VOLUME \{25, (1), pp. .

Carley K. and Prietula M. (1992). Toward a Cognitively Motivated Theory of Organizations. Proceedings of the 1992 Coordination Theory and Collaboration Technology Workshops: Symposium Conducted for the National Science Foundation.

Carley K. and M. Prietula. (forthcoming). ACTS Theory: Extending the Model of Bounded Rationality. In Carley and Prietula (Eds.), Computational Organization Theory. Hillsdale, NJ: Lawrence Erlbaum Assoc.

Carley K., Kjaer-Hansen J., Prietula M., and Newell A. (1992). Plural-Soar: A Prolegomenon to Artificial Agents and Organizational Behavior. In Masuch M. and M. Warglien (Eds.), Artificial Intelligence in Organization and Management Theory. Amsterdam, The Netherlands: Elsevier Science Publishers.

Cyert R.M. and J.G. March. (1963). A Behavioral Theory of the Firm. Englewood Cliffs, NJ: Prentice-Hall.

Cohen M.D. (1986). Artificial Intelligence and the Dynamic Performance of Organizational Designs. In March J.G. and R. Weissinger-Baylon (Eds.), Ambiguity and Command: Organizational Perspectives on Military Decision Making. Marshfield, MA: Pitman.

Cohen, M. D., March, J. B and J. P. Olsen (1972), "A Garbage Can Model of Organizational Choice," Administrative Science Quarterly, 17(1):1-25.

Corkill D. (1979). Hierarchical planning in a distributed environment. Proc.Sixth Int. Joint Conf. on Artificial Intelligence. Tokyo, Japan.

Chorafas, Dimitris N. (1965), Systems and Simulation, New York: Academic Press.

Crecine, J. P. (1969), "A Computer Simulation of Municipal budgeting," Rand McNally, Chicago, IL.

Crowston Kevin (1994), "Evolving Novel Organizational Forms," In Kathleen Carley and Michael Prietula (Eds.) Computational Organization Theory, Lawrence Erlbaum Associates, Hillsdale, NJ.CHAP3 
Davis R. and R.G. Smith. (1983). Negotiation as a metaphor for distributed problem solving. Artificial Intelligence, 20, 63-109.

DeGroot M.H. (1970). Optimal Statistical Decisions. New York, NY: McGraw-Hill.

DeGroot M.H. (1974). "Reaching a Consensus." Journal of American Statistical Association, 69, 118-121.

Decker, Keith S. and Lesser, Victor R. (1992), "Generalizing the Partial global Planning algorithm," International Journal of Intelligent and Cooperative Information Systems 1 (2) : 319-346.

Decker, Keith S. and Lesser, Victor R. (1993a), "Analyzing a Quantitative Coordination Relationship," Group Decision and Negotiation 2(3) : 195-217.

DiMaggio, Paul and Walter W. Powell, 1983, "The Iron Cage Revisited: Institutional Isomorphism and Collective Rationality in Organizational Fields," ASR, pp. 147-60.

DiMaggio, Paul J. 1986. "Structural Analysis of Organizational Fields: A Blockmodel Approach." Research in Organizational Behavior, 8:335-370.

Durfee E.H. (1988). Coordination of Distributed Problem Solvers. Boston, MA: Kluwer Academic Publishers.

Dutton J.M. and W. H. Starbuck, (1971) Computer Simulation of Human Behavior. New York: Wiley.

Fayol H. (1949). General and Industrial Management. (C. Storrs, Trans.) London: Kegan Paul International.

Forrester, J. W. (1961). Industrial Dynamics. Cambridge, MA: MIT Press.

Forrester, Jay Wright (1968), Principles of Systems : Text and Workbook, by Jay W. Forrester," Cambridge, Mass., Wright-Allen Press c1968.

Galbraith, Jay R., (1977). Organization Design, Addison-Wesley Publishing Company.

Gasser, Les, Ingemar Hulthage, Brian Leverich, Jon Lieb, and Ann Majchrzak, (1993) “'Organizations as Complex, Dynamic Design Problems,", in Miguel Filgueiras and 
Luis Damas, eds. Progress in Artificial Intelligence Lecture Notes in Artificial Intelligence 727, Springer Verlag.

Gasser Les and Ann Majchrzak, “ACTION Integrates Manufacturing Strategy, Design, and Planning", in P. Kidd and W. Karwowski, eds, Ergonomics of Hybrid Automated Systems $I V$, IOS Press, Netherlands, 1994.

Gasser, Les and Ann Majchrzak, "HITOP-A: Coordination, Infrastructure, and Enterprise Integration." \{lem Proceedings of the First International Conference on Enterprise Integration \}, Hilton Head, South Carolina, June, 1992 (MIT Press).

Gasser, Les and Ishida, Toru (1991), "A Dynamic Organizational Architecture for Adaptive Problem Solving," In Proceedings of the Ninth National Conference On Artificial Intelligence, Anaheim. 185-190.

Gasser, L. and Huhns, M. N. (eds.) (1989), Distributed Artificial Intelligence. Vol. 2, Morgan Kaufmann.

Glance, Natalie S. and Bernardo A. Huberman (1994a), "Dynamics of Social Dilemmas," Scientific American.

Glance Natalie S. and Bernardo A. Huberman (1994b), "Social Dilemmas and Fluid Organizations," In Kathleen Carley and Michael Prietula (Eds.) Computational Organization Theory, Lawrence Erlbaum Associates, Hillsdale, NJ.CHAP 11

Glance, Natalie s. and Bernardo A. Huberman (1993), "The Outbreak of Cooperation," Journal of Mathematical Sociology, 17(4): 281-302.

Gloves T. and J. Ledyard. (1977). Optimal Allocations of Public Goods: A Solution to the Free-Rider Problem. Econometrica, 45, 738-809.

Haberstroh, C. J. (1965). Organizational Design and Systems Analysis. In J. March (Ed.), Handbook of Organizations. Chicago, IL: Rand McNally.

Hage, J. (1965). An axiomatic theory of organizations, Administrative Science Quarterly, 10, 289-320.

Hanneman, R. (1988), Computer-Assisted Theory Building: Modeling Dynamic Social Systems, Beverly Hills, CA: Sage. 
Hanneman, R., Collins, R., Mordit, G. (1992), "Long-Term Dynamics of state Legitimacy and Imperialist Capitalism: A Simulation of Neo-Weberian Theory, Unpublished Paper, Riverside, CA.

Harrison J.R. and G.R. Carrol. (1991). Keeping the Faith: A Model of Cultural Transmission in Formal Organizations. Administrative Science Quarterly, 36, 552-582.

Heise D. (1978). Computer-Assisted Analysis of Social Action (Tech. Rep.). Chapel Hill, N.C. Institute for Research in Social Science,

Heise D. (1979). Understanding Events: Affect and the Construction of Social Action. New York, NY: Cambridge University Press.

Heise D. (1987). Affect Control Theory: Concepts and Model.S Journal of Mathematical Sociology, 13: 1-34.

Jin, Y. and Levitt, R. E. (1994), "i-AGENTS : Modeling Organization Problem Solving in Multiagent Teams," International Journal of Intelligent Systems in Accounting, Finance and Management.

Judson, D. H. (1993), "Simulation of Social Systems: An Application of System Dynamics Modelling to Impact Analysis of the Oregon Employment Department Information Network," Proceedings of the Sixth Annual Theory and Research on Group Processes Conference, Miami.

Kaufer D. and K. Carley. (1993), Communication at a Distance: The Effect of Print on SocioCultural Organization and Change. Hillsdale, NJ: Lawrence Erlbaum Associates.

Krackhardt D. (1994). Graph Theoretical Dimensions of Informal Organizations. In Carley K. and M. Prietula (Eds.), Computational Organization Theory. Hillsdale, NJ: Lawrence Erlbaum Associates.

Lant, Theresa K. (1994), "Computer Simulations of Organizations as Experimental Learning Systems: Implications for Organization Theory," In Kathleen Carley and Michael Prietula (Eds.) Computational Organization Theory, Lawrence Erlbaum Associates, Hillsdale, NJ.

Lant, Theresa L. and Mezias, Stephen J. (1990), "Managing Discontinuous Change: A Simulation Study of Organizational Learning and Entrepreneurship," Strategic Management Journal, Vol. 11, 147-179. 
Lant, Theresa L. and Mezias, Stephen J. (February 1992), "An Organizational Learning Model of Convergence and Reorientation," Organization Science, Vol. 3 No.1: 47-71.

Lawrence P.R. and J. Lorsch. (1967). Organization and Environment: Managing Differentiation and Integration. Boston, MA: Harvard University.

Levitt Raymond E. , Geoffrey P. Cohen, John C. Kunz, Clifford I. Nass, Tore Christiansen and Yan Jin (1994), "The 'Virtual Design' Team: Simulating How Organization Structure and Information Processing Tools Affect Team Performance," In Kathleen Carley and Michael Prietula (Eds.) Computational Organization Theory, Lawrence Erlbaum Associates, Hillsdale, NJ.CHAP 2

Lin, Zhiang (1994), Organizational Performance: Theory and Reality. PhD Thesis. Carnegie Mellon University.

Lin, Zhiang (1994), "A Theoretical Evaluation Of Measures Of Organizational Design: Interrelationship And Performance Predictability," In Kathleen Carley and Michael Prietula (Eds.) Computational Organization Theory, Lawrence Erlbaum Associates, Hillsdale, NJ.CHAP 7

Lin Z. and K. Carley. (forthcoming). Proactive or Reactive: An Analysis of the Effect of Agent Style in Accounting, Finance and Management. International Journal of Intelligent Systems in Accounting, Finance and Management, .

Macy M. W. (1990), "Learning Theory and the Logic of Critical Mass," American Sociological Review. 55:809-826.

Macy M. W. (1991), "Learning to Cooperate: Stochastic and Tacit Collusion in Social Exchange," American Journal of Sociology. 97(3): 808-43.

Majchrzak Ann, and Linda Finley, (1995). "A Practical Theory and Tool for Specifying Sociotechnical Requirements to Achieve Organizational Effectiveness," in J.J. Benders, J. De Haan, and D. Bennett, (eds.) Symbiotic Approaches: Work and Technology, Taylor and Francis, London.

Majchrzak Ann and Les Gasser, (1992)." Towards a Conceptual Framework for Specifying Manufacturing Workgroups Congruent with Technological Change," International Journal of Computer-Integrated Manufacturing, 5:2, pp. 118-131. 
Majchrzak Ann and Les Gasser, (1992). "HITOP-A: A Tool to Facilitate Interdisciplinary Manufacturing Systems Design," International Journal of Human Factors in Manufacturing, 2:3, pp 255-276.

Majchrzak Ann and Les Gasser, (1991). “On Using Artificial Intelligence to Integrate the Design of Organizational and Process Change in US Manufacturing" Artificial Intelligence and Society 5, pp: 321-338.

Malone T.W. (1987). Modeling Coordination in Organizations and Markets. Management Science, 33, 1317-1332.

Marschak J. (1955). Elements for a Theory of Teams. Management Science, 1, 127-137.

March J. and R. Weissinger-Baylon (Eds.). (1986). Ambiguity and Command: Organizational Perspectives on Military Decision Making. Boston, MA: Pitman.

March J. and J.P. Olsen. (1976). Ambiguity and Choice in Organizations. Bergen, Norway: Universitetsforlaget.

March J. and H. Simon. (1958). Organizations. New York, NY: Wiley.

Masuch, Michael (1990), Organization, Management and Expert Systems: Models of Automated Reasoning, Walter de Gruyter, Berlin, New York.

Masuch M. and P. LaPotin. (1989). Beyond Garbage Cans: An AI Model of Organizational Choice. Administrative Science Quarterly, 34, 38-67.

Mezias, S.J. \& Glynn, M.A. (1994). Using computer simulation to understand the management of technology: Applications for theory development. Technology Studies, forthcoming.

Patrick S. (1974). "Complex Model Variations: The Affects of Selected Parameter Changes to Simulation Outcomes" Paper presented at the ORSA/TIMS workshop on Mathematical and Computational Organization Theory.

Perrow C. (1984). Normal Accidents: Living with High Risk Technologies. New York, NY: Basic Books, Inc.

Reuter, Perrin, Mitchell, Benett, and Grimes, (1994). "The Training Impact Decisions System (TIDES) A Decision-Aiding System for Personnel Utilization and Training in U.S. Air Force 
Occupational Specialties" Paper presented at the ORSA/TIMS Workshop on Mathematical and Computational Organization Theory.

Rogers, W. P., et al., Report of the Presidential Commission on the Space Shuttle Challenger Accident, Government Printing Office, Washington, D. C., 1986.

Shrivastava, Paul, Bhopal: Anatomy of a Crisis. Cambridge, Ballinger Pub. Co., Mass., 1987.

Staw, Barry M., Lance E. Sanderlands and Jane E. Dutton, (1981). "Threat-Rigidity Effects in Organizational Behavior: A Multilevel Analysis," Administrative Science Quarterly, 26, 501524.

Taylor Frederick. (1911). The Principles of Scientific Management. New York: Harper and Row.

Thompson, James D.,1962/67, Organizations in Action. McGraw-Hill.

Tsuchiya, Shigehisa (1993), "Artificial Intelligence and Organizational Learning: How Can AI Contribute to Organizational Learning?," Working Paper.

Weber M. (1922). Bureaucracy. In Gerth H. and C.W. Mills (Eds.), Max Weber: Essays in Sociology. Oxford, England: Oxford University Press.

Weber M. (1968). Economy and Society. New York, NY: Bedminster Press.

Wolfe, Alan (1991) "Mind, Self, Society, and Computer: Artificial Intelligence and Sociology of Mind," American Journal of Sociology, Vol. 96, No. 5: 1073-96. 